\title{
A NOVA NATUREZA JURÍDICA DA ÁGUA E SUAS CONSEQUÊNCIAS EM FACE DA OUTORGA DE DIREITO DE USO DE RECURSOS HÍDRICOS
}

\section{THE NEW JURIDICAL NATURE OF WATER AND ITS CONSEQUENCES FACING THE GRANT OF THE WATER RESOURCES` RIGHT OF USE}

\begin{abstract}
Tony CaRlo Souza SiLva Graduado em Direito; pós-graduando lato sensu em Gestão Ambiental: Diagnóstico e Adequação Ambiental, pelo Instituto Federal do Triângulo Mineiro IFTM campus Uberaba. Atualmente, participa da Iniciação Científica -IC- em Educação Ambiental, é, ainda, aluno bolsista do projeto de extensão pela IFTM, bem como é Advogado Junior inscrito na OAB sob o $n^{\circ}$ de ordem: 143197
\end{abstract}

JOHNSON QUEIROZ VILAS BOAS

Possui graduação em Administração pela Faculdade de Ciências Econômicas do Triângulo Mineiro (2009). Pósgraduando (lato sensu) em Gestão Empresarial e Gestão de Pessoas pelo Instituto Catarinense de Pós-graduação (ICPG - Uniasselvi - Instituto Passo 1). Pós-graduando (lato sensu) em Gestão Ambiental pelo Instituto Federal de Educação Ciência e Tecnologia do Triângulo Mineiro (IFTM). Graduando em Ciências Contábeis pela Universidade de Franca (UNIFRAN). Sócio na Empresa Solidez Contabilidade Ltda - Uberaba/MG tem experiência principalmente na área fiscal/tributária.

\section{RESUMO}

A água, por ser um elemento escasso e facilmente deteriorável, merece hoje destaque no que tange à sua preservação e conservação. Este artigo elenca os novos aspectos legais referentes aos Recursos Hídricos que definem a água como bem de uso comum do povo, sendo essencial para a existência dos seres vivos. Elenca as consequências da nova dimensão jurídica que a Constituicão da República Federativa do Brasil de 1988 (CRFB/88) trouxe à água, sendo esta um bem difuso e transindividual, ou seja, água pertence a todos e ao mesmo tempo não pertence a ninguém, não configurando assim Patrimônio do Poder Público que tem apenas a incumbência de geri-la. A partir da premissa da Gestão Pública, a Política Nacional de Recursos Hídricos surge implementando a outorga como ferramenta de extremo valor, sendo, por meio dela, possível distribuir de forma mais justa, controlar e fiscalizar o uso dos recursos hídricos. Para a elaboração desse artigo procedeu-se à revisão bibliográfica como metodologia.

Palavras-chave: água; outorga; recursos hídricos.

\begin{abstract}
The water, as an element scarce and perishable, deserves today highlighted regarding the preservation and conservation. This article lists the new legal aspects relating to water resources that define water as a common use, is essential for the existence of living beings. Lists the legal implications of the new dimension that the Constitution of the Federative Republic of Brazil 1988 (CRFB/88) brought the water, which is a diffuse and transindividual, ie, water belongs to everyone and at the same time belongs to no one, not thus setting Heritage of the Government which has only the task of managing it. From the premise of the National Public Management of Water Resources arises, implementing the grant as a tool of extreme value, and, through it, can distribute more fairly, control and monitor the use of water resources. For the preparation of this article proceeded to the literature review and methodology.
\end{abstract}

Keywords: water; grant; resources. 


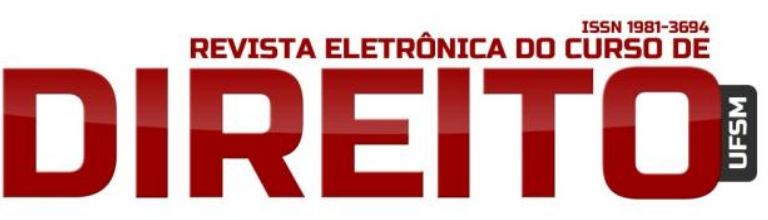

A NOVA NATUREZA JURÍDICA DA ÁGUA E SUAS CONSEQUÊNCIAS EM FACE DA OUTORGA DE DIREITO DE USO DE RECURSOS

HÍDRICOS.

\section{SUMÁRIO}

INTRODUÇAO; 1 ASPECTOS LEGAIS PERTINENTE AO RECURSO HÍDRICO; 1.1 Água: bem de uso comum do povo; 1.2 Competência Legislativa; 1.3 Competência material; 2 OUTORGA DE DIREITO DE USO DE RECURSOS HÍDRICOS; 2.1 Recursos hídricos passíveis e independentes de outorga, usos insignificantes e outorga preventiva; 2.2 Prazos de vigência e suspensão das outorgas; 2.3 Competência para autorização de outorgas; CONCLUSÃO; REFERÊNCIAS BIBLIOGRÁFICAS.

\section{INTRODUÇÃO}

A água é um recurso natural integrante do meio ambiente natural. Trata-se de um bem imprescindível e insubstituível, essencial às funções vitais do ser humano, ao desenvolvimento econômico, à preservação dos seres vivos.

A escassez da água poderá, dentre outros, interferir direta e indiretamente no equilíbrio dinâmico dos ecossistemas, de modo a prejudicar a biota a funcionar à base da complementaridade e na interdependência. Destarte, os aspectos qualitativos e quantitativos da água estão ligados intimamente com as dimensões ambientais, econômicos, sociais, culturais de um país.

Com isso, e somado à percepção da finitude dos recursos naturais, e às preocupações quanto ao modelo tecnológico de desenvolvimento adotado pela sociedade contemporânea que gerou grandes impactos negativos no âmbito ambiental, urge à necessidade de regular o uso dos recursos naturais, a fim de assegurar a própria existência dos seres vivos. Sensível a tal fato, eis que surge, em 1988, a Constituição da República Federativa do Brasil - CRFB/88 - a qual inovou conceitos jurídicos referentes aos recursos naturais e contemplou novos direitos, dentre eles, o direito ao meio ambiente ecologicamente equilibrado, essencial a uma saudável qualidade de vida. Este último é um direito fundamental (difuso) da $3^{\circ}$ dimensão que consagra o postulado da solidariedade ou fraternidade do pós-segunda guerra mundial.

Em determinadas situações, a água é compreendida como um bem público, por outro lado, em outras situações é entendida como bem privado; eis que surge a indagação quanto à sua natureza. Afinal, a água é um bem público, privado ou é um bem difuso? A água se revela como um bem difuso, de uso comum do povo. Trata-se de um bem que apresenta como um direito transindividual, de natureza indivisível, cuja titularidade é indeterminada e interligada 


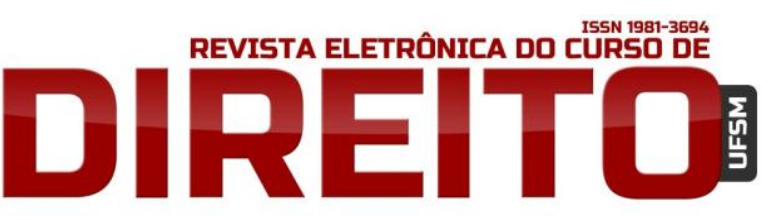

A NOVA NATUREZA JURÍDICA DA ÁGUA E SUAS CONSEQUÊNCIAS EM FACE DA OUTORGA DE DIREITO DE USO DE RECURSOS

HÍDRICOS.

TONY CARLO SOUZA SILVA JOHNSON QUEIROZ VILAS BOAS

por circunstâncias de fato. A água, portanto, pertence a todos, mas, ao mesmo tempo, não é de ninguém em específico, dada sua transindividualidade. A partir daí, verifica-se que a água não integra o patrimônio do Poder Público, este é apenas o seu gestor no interesse de todos.

Outrossim, afigura-se patente que a efetivação de todos os outros direitos fundamentais assegurados pela CRFB/88 gravitam em torno do direito ao meio ambiente ecologicamente equilibrado. Isto é, o gozo do direito à saúde, por exemplo, exige necessariamente que o indivíduo esteja inserido em um meio ecologicamente sadio e equilibrado. Assim, por via de consequência, infere-se que o não acesso à água põe em xeque a efetivação de diversos direitos fundamentais, dentre eles, à integridade física, à saúde, à vida, ao respeito à dignidade da pessoa humana. É nesse sentido que reside à relevância do presente artigo.

0 presente artigo, portanto, tem o intuito de elencar as consequências práticas da nova dimensão jurídica que a CRFB/88 trouxe ao meio ambiente no que tange ao elemento vital água. Neste sentido, pretende-se apresentar o contexto da natureza jurídica de um dos instrumentos utilizados na gestão de recursos hídricos, qual seja: outorga de direito de uso de recurso hídrico, abordando a estruturação e a sistematização do processo administrativo, além de identificar quais são os órgãos responsáveis pela concessão da autorização, como também as consequências de sua implementação no tocante ao desenvolvimento econômico, equidade social e equilíbrio ecológico, uma vez que o objetivo deste mecanismo é garantir que a água esteja disponível em quantidade e qualidade adequada para o uso das presentes e futuras gerações. Desta forma, para a confecção do artigo em foco procedeu-se à revisão bibliográfica como metodologia.

\section{ASPECTOS LEGAIS PERTINENTE AO RECURSO HÍDRICO}

\section{1 Água: bem de uso comum do povo.}

A Constituição da República Federativa do Brasil de 1988 (CRFB/88) assegura a todos o direito ao meio ambiente ecologicamente equilibrado, bem de uso comum do povo e essencial à sadia qualidade de vida. É o que dita o caput do art. 225 da Carta Magna, literis:

Art. 225 - Todos têm direito ao meio ambiente ecologicamente equilibrado, bem de uso comum do povo e essencial à sadia qualidade de vida, impondo-se ao 
Poder Público e à coletividade o dever de defendê-lo e preservá-lo para as presentes e futuras gerações. ${ }^{1}$ (Grifo nosso)

Percebe-se pela simples leitura da norma constitucional supramencionada que a CRFB/88 trouxe uma nova dimensão ao conceito do meio ambiente, classificando-o como bem de uso comum do povo. Tal conceito não elimina a antiga percepção de bem público ou bem privado, mas o amplia, visto que se trata de nova categoria denominada de bem difuso. Isso porque introduziu-se a função social e ambiental da propriedade como princípio da gestão do meio ambiente. $^{2}$

O direito ao meio ambiente ecologicamente equilibrado é classificado, em conformidade com o surgimento social e reconhecimento nos ordenamentos jurídicos, como um direito fundamental da $3^{\circ}$ dimensão (ou geração), que contempla os direitos difusos, inserido na amplitude do direito da solidariedade ou fraternidade. ${ }^{3}$ Em outras palavras, o meio ambiente é um direito difuso, uma vez que se encontra difundido pela coletividade. Portanto, o meio ambiente pertence a todos, mas, ao mesmo tempo, ninguém especificamente o possui. ${ }^{4}$

Nesse diapasão, Sirvinskas ensina que o bem ambiental não pode ser inserido na classificação de bem público nem como bem privado - àqueles previstos no art. 98 do CC/2002. ${ }^{5}$ Isto porque o meio ambiente refere-se a uma terceira categoria de bem, situada numa faixa intermediária entre o público e o privado, denominando-se bem difuso. ${ }^{6}$

Corroborando com esse entendimento, Yoshida ensina que os bens ambientais são bens difusos, de uso comum do povo. Portanto, não são bens públicos (bens dominicais), pertencentes ao patrimônio público. Em verdade, são bens que estão sob a administração dos entes públicos (administração direta e indireta). ${ }^{7}$ Por isso, o direito ao meio ambiente entra na

\footnotetext{
${ }^{1}$ BRASIL.Constituição da República Federativa do Brasil de 1988. Diário Oficial [da República Federativa do Brasil], Brasília, DF. Disponível em: <http://www.planalto.gov.br/ccivil_03/constituicao/ constituicaocompilado.htm>. Acesso em: 26 abr. 2013.

2 MACHADO, Paulo Affonso Leme. Curso de Direito Ambiental Brasileiro. 17. ed. São Paulo: Malheiros, 2009.

3 TERZI, Alex Mourão; PEREIRA, Pedro Henrique Santana. Educação Ambiental como Direito Fundamental: necessidade de uma abordagem interdisciplinar 2011.

${ }^{4}$ FIORILLO, Celso Antonio Pacheco. Curso de direito ambiental brasileiro. 13. ed. rev., atual. e ampl. São Paulo: Saraiva, 2012.

${ }^{5}$ BRASIL. Lei $\mathrm{n}^{\circ}$ 10.406, de 10 de janeiro de 2002. Institui o Código Civil. Diário Oficial [da República Federativa do Brasil], Brasília, DF. Disponível em: <http://www.planalto.gov.br/ccivil_03/leis/2002/l10406.htm>. Acesso em: 24 jul. 2013.

${ }^{6}$ SIRVINSKAS, Luís Paulo. Manual de Direito Ambiental. 7.ed. São Paulo: Saraiva, 2009.

7 YOSHIDA, Consuelo Yatsuda Moromizato. Água: bem privado, bem público ou bem difuso. Implicações jurídicas, econômico-financeiras e sócio-ambientais. Recursos Hídricos: aspectos éticos, jurídicos, econômicos e socioambientais. v. 2. Campinas: Alínea, 2007.
} 
categoria de interesse difuso, visto que não se esgota num só indivíduo, e sim se difunde para uma coletividade indeterminada. ${ }^{8}$

Com base em tais informações, cumpre-nos destacar que o recurso hídrico é um bem corpóreo (material), elemento integrante do ambiente em estado natural, logo a água é um bem de uso comum do povo. Desta forma, dessume-se que a água não é bem público, e muito menos privado. A água é, destarte, um bem que possui natureza transindividual, ou seja, transcendem o indivíduo, ultrapassa o limite da esfera de direitos e obrigações de cunho individual. ${ }^{9}$ Não se pode olvidar então que, desde o advento da CRFB/88, a água deixou de ser considerada bem público; passando, assim, a ser considerada como um bem de natureza jurídica difuso, como dito anteriormente.

Em consequência desta "reclassificação" ora apresentada, pode-se afirmar que a água, destarte, não integra o patrimônio privado do Poder Público. Isso porque se trata de um bem inalienável. A outorga, por exemplo, não implica a alienação parcial das águas, mas o seu simples direito de uso, é o que assevera o art. 18 da Lei $9.433 / 97 .{ }^{10}$ Cabe tão-somente ao Poder Público o papel de gestor de recursos hídricos.

Elencamos, neste momento, algumas consequências diante desta nova dimensão jurídica que a CRFB/88 trouxe ao meio ambiente no que tange ao elemento vital água: 1) inviabilidade de privatização de mercantilização dos recursos hídricos; 2) a água não pode ser apossada por uma só pessoa, seja física ou jurídica, que resulte na exclusão absoluta aos demais usuários de usufruir de tal direito; 3) cabe a todos o dever de defendê-la e preservá-la para as presentes e futuras gerações, visto que o meio ambiente ecologicamente equilibrado é um direito intergeracional; 4) repúdio a qualquer forma de poluição ou agressão deste bem natural; 5) uso racional dos recursos hídricos, como também devemos reutilizá-lo, isso porque não podemos esgotá-lo; 6) qualquer tipo de outorga do uso (concessão ou autorização) da água deve ser rigorosamente motivada e fundamentada pelo gestor público; 7) a água não integra o patrimônio

\footnotetext{
8 MACHADO, Paulo Affonso Leme Curso de Direito Ambiental Brasileiro. 17. ed. São Paulo: Malheiros, 2009.

${ }^{9}$ FIORILLO, Celso Antonio Pacheco. Curso de direito ambiental brasileiro. 13. ed. rev., atual. e ampl. São Paulo: Saraiva, 2012.

${ }^{10}$ BRASIL. Lei $\mathrm{n}^{\circ}$ 9.433, de 8 de janeiro de 1997. Institui a Política Nacional de Recursos Hídricos, cria o Sistema Nacional de Gerenciamento de Recursos Hídricos, regulamenta o inciso XIX do art. 21 da Constituição Federal, e altera o art. $1^{\circ}$ da Lei $n^{\circ} 8.001$, de 13 de março de 1990 , que modificou a Lei $n^{\circ}$ 7.990, de 28 de dezembro de 1989. Diário Oficial [da República Federativa do Brasil], Brasília, DF. Disponível em: <http://www.planalto.gov.br/ccivil_03/leis/L9433.htm>. Acesso em: 26 abr. 2013.
} 
privado do poder público, este é apenas o gestor (dominialidade) dos recurso hídricos; dentre outros.

Por fim, pode-se dizer em suma que: a CRFB/88 contempla três categorias distintas de bens, a saber: os privados, os públicos e os difusos. É nesse último que se encontra inserida a classificação da natureza jurídica da água. Importa ressaltar, ainda, que o destinatário do direito ao meio ambiente ecologicamente equilibrado - aí inserido o elemento vital: água - são todas as pessoas. ${ }^{11} \mathrm{E}$, além do mais, cabe ao Poder Público, como à coletividade o dever de defendê-lo e preservá-lo para as presentes e futuras gerações.

\subsection{Competência legislativa}

Em matéria de competência legislativa, a CRFB/88 tratou sobre as águas em mais de um dispositivo, conforme veremos, mais detidamente, nas próximas linhas.

Em primeiro momento, a CRFB/88 fixou à União a competência para legislar privativamente sobre a água. É o que dita o art. 22, inciso IV ${ }^{12}$, in verbis: “Art. 22. Compete privativamente à União legislar sobre: [...] IV - águas, energia, informática, telecomunicações e radiodifusão."

Contudo, após a leitura de alguns artigos adiante, mais precisamente no art. 24, VI, verifica-se que a CRFB/88 atribuiu à União, Estados e Distrito Federal (é a chamada competência concorrente) competência para legislar sobre meio ambiente, inserindo-se aí o elemento água. Ademais, determinou-se, também, a competência concorrente para legislar sobre responsabilidade por dano ao meio ambiente - conglobando, destarte, aspectos da poluição dos corpos d'água -, consoante o mesmo artigo em seu inciso VII. Vejamos:

\footnotetext{
Art. 24: Compete à União, aos Estados e ao Distrito Federal legislar concorrentemente sobre:

[...]

VI - florestas, caça, pesca, fauna, conservação da natureza, defesa do solo e dos recursos naturais, proteção do meio ambiente e controle de poluição,

$\mathrm{VII}$ - responsabilidade por dano ao meio ambiente $[\ldots]^{13}$
}

\footnotetext{
${ }^{11}$ NOVELINO, Marcelo; CUNHA JUNIOR, Dirley da Constituição Federal para Concursos. 2. ed. Salvador: JusPodivm, 2011.

12 BRASIL.Constituição da República Federativa do Brasil de 1988. Diário Oficial [da República Federativa do Brasil], Brasília, DF. Disponível em: <http://www.planalto.gov.br/ccivil_03/constituicao/constituicaocompilado.htm>. Acesso em: 26 abr. 2013.

${ }^{13}$ BRASIL. Constituição da República Federativa do Brasil de 1988, op. cit.
} 
Percebe-se que a CRFB/88 possibilitou várias interpretações quanto à competência legislativa no tocante às águas. Diante desse quadro confuso, pergunta-se: afinal de contas, de quem é a competência legislativa para legislar sobre matérias pertinentes à água? A melhor interpretação a ser feita, salvo melhor juízo, é no sentido de que cabe à União legislar sobre normas gerais; aos Estados e ao Distrito Federal legislar complementarmente; e, por fim, compete ao Município suplementar a legislação federal e a estadual no que couber - consoante art. 30, inciso II, da CRFB/88. Nesse sentido se posiciona Machado ao afirmar que a normatividade dos Estados sobre a água depende do que dispuser a lei federal no que se refere aos padrões de qualidade de água, critérios de sua classificação, dentre outros. Não podendo, portanto, os Estados estabelecer, de modo inovador, novas condições para cada classe de água ou estabelecer novos sistemas de classificação. ${ }^{14}$

\subsection{Competência material}

Passaremos a analisar neste tópico, de modo sucinto, a competência material quanto à proteção dos recursos hídricos. A nossa Carta Magna estabelece em seu art. 23, inciso $\mathrm{VI}^{15}$, que é de competência comum da União, dos Estados, do Distrito Federal e dos Municípios "proteger o meio ambiente e combater a poluição em qualquer de suas formas."

Importante lembrarmos que para determinar qual ente é responsável pela aplicação das sanções, deve-se, primeiramente, averiguar se o bem a ser tutelado é de gerência da União que são àqueles previstos no art. 20 , inciso III, da CRFB $/ 88^{16}$ - ou do Estado - previstos, por sua vez, no art. 26 , inciso I, da $C R F B / 88^{17}$, para que assim o respectivo ente (responsável) possa aplicar às devidas sanções no caso concreto. É importante frisar que a competência material deverá ser cumprida por mais que o ente federado não tenha exercido sua atribuição legislativa. $^{18}$

\footnotetext{
${ }^{14}$ MACHADO, Paulo Affonso Leme. Direito ambiental brasileiro. 3. ed. São Paulo: Revista dos Tribunais, 1991. p. 50.

${ }_{15}$ BRASIL.Constituição da República Federativa do Brasil de 1988. Diário Oficial [da República Federativa do Brasil], Brasília, DF. Disponível em: <http://www.planalto.gov.br/ccivil_03/constituicao/constituicaocompilado.htm>. Acesso em: 26 abr. 2013.

${ }^{16}$ BRASIL.Constituição da República Federativa do Brasil de 1988, op. cit.

${ }^{17}$ BRASIL.Constituição da República Federativa do Brasil de 1988, op. cit.

${ }_{18}$ FIORILLO, Celso Antonio Pacheco. Curso de direito ambiental brasileiro. 13. ed. rev., atual. e ampl. São Paulo: Saraiva, 2012. p. 306.
} 


\section{OUTORGA DE DIREITO DE USO DE RECURSOS HÍDRICOS}

Uma vez abordado o tema referente à compreensão atual sobre a natureza jurídica da água, enquanto bem difuso de uso comum da coletividade, diante do advento da CRFB/88, passemos, neste tópico, a analisar a outorga do uso da água, o qual, conforme se verá mais detidamente abaixo, se revela como instrumento que visa assegurar o seu uso racional, sendo, portanto, fiel à ideologia extraída da natureza jurídica dos recursos hídricos.

Outorga de um recurso hídrico nada mais é que a autorização do poder público para que um determinado sujeito, público ou privado, se utilize privativamente do recurso hídrico, sendo um dos instrumentos da Política Nacional de Recursos Hídricos, conforme disposto no art. $5^{\circ}$, inciso III, da Lei n. ${ }^{\circ} 9.433 / 97 .{ }^{19}$ Já a Instrução Normativa n. ${ }^{\circ} 4^{20}$ do MMA - Ministério do Meio Ambiente de 21/06/00 entende a outorga como ato administrativo, sendo uma autorização na qual o Poder Público outorgante faculta ao outorgado o direito de uso do recurso hídrico, por prazo determinado, nos termos e condições expressos no respectivo ato.

Com o advento da Lei $n .^{\circ} 9.984 / 00$ em seu art. $4^{\circ}$, inciso IV ${ }^{21}$, que estabelece como sendo da Agência Nacional de Águas - ANA - a competência para outorgar por intermédio de autorização, o direito de uso dos recursos hídricos em corpos de água de domínio da União, não restou margens a dúvidas quanto à natureza da outorga no que tange a ser uma autorização ou concessão de serviço público.

A outorga vem democratizar o uso concorrente dos recursos hídricos em que pese à natureza de bem difuso, o qual, segundo Sirvinskas, pertence a cada um, e ao mesmo tempo a todos não sendo possível identificar sua titularidade e sendo seu objeto insuscetível de divisão. É

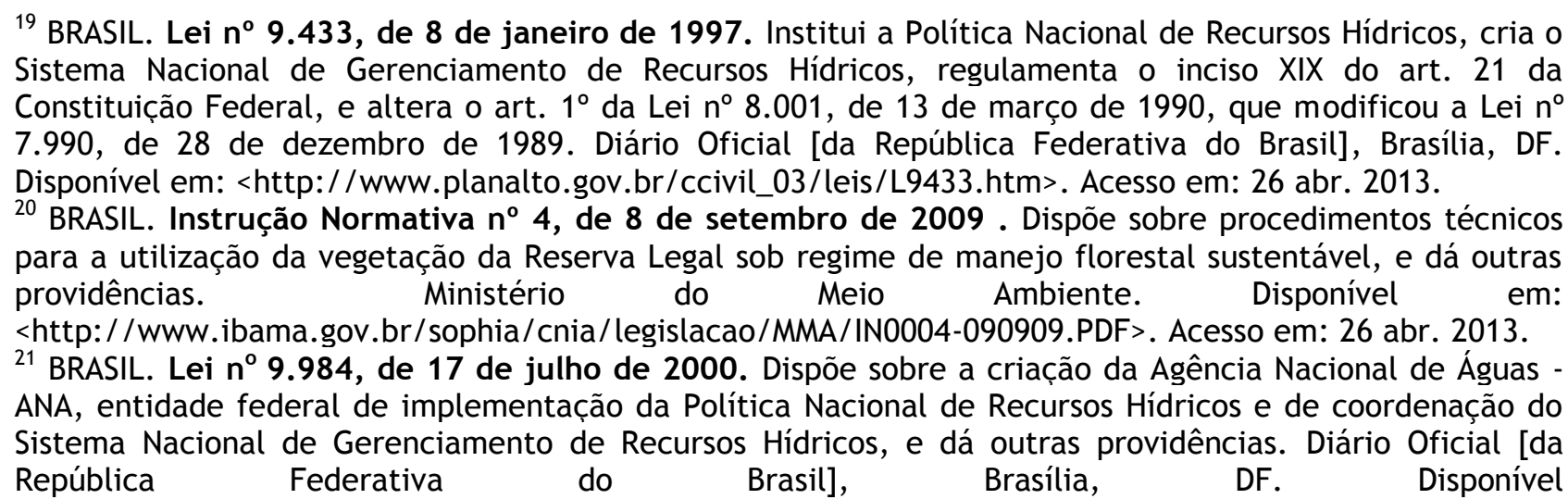
em:<http://www.planalto.gov.br/ccivil_03/leis/L9984.htm>. Acesso em: 26 abr. 2013. 
necessário destacar também a importância dos Comitês de Bacias Hidrográficas nas concessões de outorgas visto que são esses órgãos que aprovam os planos de bacias hidrográficas nos quais devem constar as prioridades. ${ }^{22}$

Outra análise em relação à outorga levando-se em conta sua natureza de bem difuso diz respeito à diferença marcante entre o Código de Águas - Decreto n. ${ }^{\circ} 24.643$ de 10 de julho de $1934^{23}$ e a Lei n. ${ }^{\circ} 9.433 / 97^{24}$.

Em seu artigo 43 o Código de Águas estabelece:

Art. 43. As águas públicas não podem ser derivadas para as aplicações da agricultura, da indústria e da higiene, sem a existência de concessão administrativa, no caso de utilidade pública e, não se verificando esta, de autorização administrativa, que será dispensada, todavia, na hipótese de derivações insignificantes.

Percebe-se que a legislação de 1934 trata sobre as derivações dos corpos de água, casos nos quais, há apenas a captação desse recurso com seu consumo ou utilização de forma que volte ao mesmo corpo de água ou a outro corpo receptor. A preocupação existia somente no que diz respeito ao balanço hídrico dos corpos de água e a outorga era utilizada no sentido de garantir esse balanceamento. A vazão dos corpos hídricos se fazia importante para que pudesse garantir a instalação de usinas hidrelétricas no país, dessa forma privilegiando um setor econômico em detrimento da sociedade e indo de encontro à natureza de bem difuso dos recursos hídricos.

Ao final da década de 1990, no sentido de mudar o enfoque da legislação e tratar os recursos hídricos como bens difusos e transindivudais, garantindo principalmente a previsão para os diversos usos da água, surgira a Lei n. ${ }^{\circ} 9.433 / 97^{25}$. Essa Lei passou a tratar os recursos hídricos não só de forma quantitativa, mas também qualitativa.

\footnotetext{
${ }^{22}$ SIRVINSKAS, Luís Paulo. Manual de Direito Ambiental. 7.ed. São Paulo: Saraiva, 2009. p. 51-52.

${ }^{23}$ BRASIL. Decreto $\mathrm{n}^{\circ}$ 24.643, de 10 de julho de 1934. Decreta o Código de Águas. Diário Oficial [da República Federativa do Brasil], Brasília, DF. Disponível em:< http://www.planalto.gov.br/ccivil_03/decreto/d24643.htm>. Acesso em: 26 abr. 2013.

${ }^{24}$ BRASIL. Lei $n^{\circ}$ 9.433, de 8 de janeiro de 1997. Institui a Política Nacional de Recursos Hídricos, cria o Sistema Nacional de Gerenciamento de Recursos Hídricos, regulamenta o inciso XIX do art. 21 da Constituição Federal, e altera o art. $1^{\circ}$ da Lei $n^{\circ} 8.001$, de 13 de março de 1990 , que modificou a Lei $n^{\circ}$ 7.990, de 28 de dezembro de 1989. Diário Oficial [da República Federativa do Brasil], Brasília, DF. Disponível em: <http://www.planalto.gov.br/ccivil_03/leis/L9433.htm>. Acesso em: 26 abr. 2013.

${ }^{25}$ Ibidem.
} 


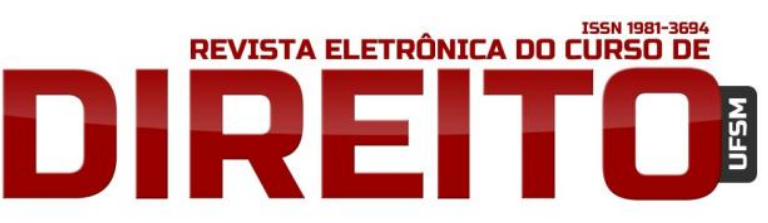

A NOVA NATUREZA JURÍDICA DA ÁGUA E SUAS CONSEQUÊNCIAS EM FACE DA OUTORGA DE DIREITO DE USO DE RECURSOS

HÍDRICOS.

TONY CARLO SOUZA SILVA JOHNSON QUEIROZ VILAS BOAS

Em seu artigo 11 a Lei n. ${ }^{\circ}$ 9.433/97 ${ }^{26}$ estabelece que "o regime de outorga de direitos de uso de recursos hídricos tem como objetivos assegurar o controle quantitativo e qualitativo dos usos da água e o efetivo exercício dos direitos de acesso à água."

Para Granziera, a forma como o Código das Águas tratava a outorga perdeu o sentido devido à evolução do Brasil com o aumento da população, urbanização e industrialização sem planejamento, sendo necessário atentar-se não só para as questões quantitativas, como também as qualitativas. $^{27}$

\subsection{Recursos hídricos passíveis e independentes de outorga, usos insignificantes e outorga preventiva}

Os incisos do artigo 12 da política Nacional de Recursos Hídricos ${ }^{28}$ são responsáveis por determinar, por meio de outorga, os seguintes direitos de uso:

Art. 12. Estão sujeitos a outorga pelo Poder público os direitos dos seguintes usos de recursos hídricos:

1 - derivação ou captação de parcela da água existente em um corpo de água para consumo final, inclusive abastecimento público ou insumo de processo produtivo;

II - extração de água de aquífero subterrâneo para consumo final ou insumo de processo produtivo;

III - lançamento em corpo de água de esgotos e demais resíduos líquidos ou gasosos, tratados ou não, com o fim de sua diluição, transporte ou disposição final;

IV - aproveitamento dos potenciais hidrelétricos;

$\mathrm{V}$ - outros usos que alterem o regime, a quantidade ou a qualidade da água existente em um corpo de água.

$\S 1^{\circ}$ Independem de outorga pelo Poder Público, conforme definido em regulamento:

I - o uso de recursos hídricos para a satisfação das necessidades de pequenos núcleos populacionais, distribuídos no meio rural;

II - as derivações, captações e lançamentos considerados insignificantes;

III - as acumulações de volumes de água consideradas insignificantes

$\S 2^{\circ} \mathrm{A}$ outorga e a utilização de recursos hídricos para fins de geração de energia elétrica estará subordinada ao Plano Nacional de recursos hídricos, aprovado na forma do disposto no inciso VIII do art. 35 desta Lei, obedecida a disciplina da legislação setorial específica.

\footnotetext{
${ }^{26}$ Ibidem.

27 GRANZIERA, Maria Luiza Machado. Direito de Águas: disciplina jurídica das águas doces. 3. ed. São Paulo: Atlas, 2006.

${ }^{28}$ BRASIL. Lei $n^{\circ}$ 9.433, de 8 de janeiro de 1997. Institui a Política Nacional de Recursos Hídricos, cria o Sistema Nacional de Gerenciamento de Recursos Hídricos, regulamenta o inciso XIX do art. 21 da Constituição Federal, e altera o art. $1^{\circ}$ da Lei $n^{\circ} 8.001$, de 13 de março de 1990 , que modificou a Lei $n^{\circ}$ 7.990, de 28 de dezembro de 1989. Diário Oficial [da República Federativa do Brasil], Brasília, DF. Disponível em: <http://www.planalto.gov.br/ccivil_03/leis/L9433.htm>. Acesso em: 26 abr. 2013.
} 
A outorga tem a finalidade de controle e fiscalização dos usos dos recursos hídricos baseado no Plano de Recursos Hídricos definido para cada bacia hidrográfica pelo respectivo Comitê de Bacia. Para Machado, os governos não podem autorizar usos que agridam a quantidade e a qualidade da água e devem ter equidade na autorização dos usos, pois a outorga é o instrumento capaz de controlar o uso racional da água, controle esse ligado à escassez e à poluição do recurso. ${ }^{29}$ Também para Granziera, a escassez de água é responsável pela necessidade de controle nos usos e à medida que o recurso diminui, por ser finito, torna-se passível de valoração econômica e passa a ser questão de sobrevivência. ${ }^{30}$ Ainda para Machado, o Poder Público não é proprietário dos bens ambientais, mas sim gestor dos bens que não são dele e deve explicar de forma convincente sua gestão justamente por estar tratando de um bem difuso do qual a sociedade é tão dependente. ${ }^{31}$

Num contraponto existem recursos hídricos que independem de outorga. 0 art. 12 , § $1^{\circ}$ da Lei $n^{\circ} 9.433 / 97^{32}$, já descrito, estabelece os usos de recursos hídricos que independem de outorga, sendo estes constituídos por usos essenciais para a existência dos seres vivos dos quais é indispensável à água, esses usos abrangem as primeiras necessidades como a dessedentação humana e de animais e os cuidados básicos com a higiene. Nesse sentido, o Código das Águas de $1934^{33}$ e a Lei n. ${ }^{\circ} 9.433 / 97^{34}$, não são divergentes, trazendo em suma significâncias semelhantes.

Ainda assim, mesmo considerado uso independente de outorga, se faz necessário o registro e fiscalização por parte do Poder Público no que se refere aos usos concorrentes, para que utilização do recurso por alguns não fira a transindividualidade do bem.

Como uma terceira vertente, surge à classificação dos usos insignificantes, esses nada mais são que usos que, devido a seu pequeno impacto ficam dispensados da exigência da

29 MACHADO, Paulo Affonso Leme. Curso de Direito Ambiental Brasileiro. 17. ed. São Paulo: Malheiros, 2009. p. 471.

${ }^{30}$ GRANZIERA, Maria Luiza Machado. Revista do Centro de Estudos Judiciários. Brasília. n 12, p. 71 -74, set/dez. 2000. p. 72-73.

${ }^{31}$ MACHADO, Paulo Affonso Leme, op. cit. p. 447.

32 BRASIL. Lei ${ }^{\circ}$ 9.433, de 8 de janeiro de 1997. Institui a Política Nacional de Recursos Hídricos, cria o Sistema Nacional de Gerenciamento de Recursos Hídricos, regulamenta o inciso XIX do art. 21 da Constituição Federal, e altera o art. $1^{\circ}$ da Lei $n^{\circ} 8.001$, de 13 de março de 1990 , que modificou a Lei $n^{\circ}$ 7.990, de 28 de dezembro de 1989. Diário Oficial [da República Federativa do Brasil], Brasília, DF. Disponível em: <http://www.planalto.gov.br/ccivil_03/leis/L9433.htm>. Acesso em: 26 abr. 2013.

${ }_{33}$ BRASIL. Decreto $\mathrm{n}^{\circ}$ 24.643, de 10 de julho de 1934. Decreta o Código de Águas. Diário Oficial [da República Federativa do Brasil], Brasília, DF. Disponível em:< http://www.planalto.gov.br/ccivil_03/decreto/d24643.htm>. Acesso em: 26 abr. 2013.

${ }^{34}$ BRASIL. Lei $n^{\circ} 9.433$, de 8 de janeiro de 1997, op. cit. 
outorga. A Lei n. ${ }^{\circ}$ 9.433/97 não especifica nem quantifica o uso insignificante ficando a cargo de cada Comitê de Bacia hidrográfica ou legislação estadual a regulamentação sobre o assunto. A partir disso, surgem as mais variadas definições de vazões máximas para enquadramento nas faixas de uso insignificante. Para Machado, o critério de insignificância não poderá ser o mesmo para todas as bacias, pois é necessário levar em consideração fatores como diferenças de vazão entre corpos de água, estações do ano, grau de poluição e metas de melhoria de cada bacia a ser analisada e não obstante a isso ainda é necessário o controle e fiscalização por parte do Poder Público. ${ }^{35}$

Com a necessidade de utilização do recurso hídrico em empreendimentos, muitas vezes de grande porte, foi previsto a possibilidade da outorga preventiva, que tem a finalidade de registrar a disponibilidade de água de um determinado corpo de água para um uso solicitado, normalmente durante o planejamento de um empreendimento com um tempo determinado não ultrapassando o limite máximo de três anos. A outorga preventiva não concede direito de uso e é utilizada apenas para reservar a vazão hídrica passível de outorga. Pela natureza de bem difuso do recurso hídrico, ou seja, pertencer a todos e ao mesmo tempo não ser de ninguém é necessário que o Poder Público garanta um saldo hídrico capaz de atender às necessidades da coletividade, dessa forma não é possível conceder todas as solicitações de outorga. A outorga preventiva advém da Lei n. ${ }^{\circ} 9.984 / 00$ em seus artigos $6^{\circ}$ e $7^{\circ} \cdot{ }^{36}$

\subsection{Prazos de vigência e suspensão das outorgas}

Os prazos para as outorgas são regidos pela Lei n. ${ }^{0} 9.433 / 97^{37}$ e Lei $n .^{\circ} 9.984 / 00 .^{38} 0$ prazo máximo de vigência da outorga é de 35 anos a partir da publicação do ato administrativo

35 MACHADO, Paulo Affonso Leme Curso de Direito Ambiental Brasileiro. 17. ed. São Paulo: Malheiros, 2009.

${ }^{36}$ BRASIL. Lei $\mathrm{n}^{\circ}$ 9.984, de 17 de julho de 2000. Dispõe sobre a criação da Agência Nacional de Águas ANA, entidade federal de implementação da Política Nacional de Recursos Hídricos e de coordenação do Sistema Nacional de Gerenciamento de Recursos Hídricos, e dá outras providências. Diário Oficial [da República Federativa do Brasil], Brasília, DF. Disponível em:<http://www.planalto.gov.br/ccivil_03/leis/L9984.htm>. Acesso em: 26 abr. 2013.

${ }^{37}$ BRASIL. Lei $n^{\circ} \mathbf{9 . 4 3 3}$, de 8 de janeiro de 1997. Institui a Política Nacional de Recursos Hídricos, cria o Sistema Nacional de Gerenciamento de Recursos Hídricos, regulamenta o inciso XIX do art. 21 da Constituição Federal, e altera o art. $1^{\circ}$ da Lei $n^{\circ} 8.001$, de 13 de março de 1990 , que modificou a Lei $n^{\circ}$ 7.990, de 28 de dezembro de 1989. Diário Oficial [da República Federativa do Brasil], Brasília, DF. Disponível em: <http://www.planalto.gov.br/ccivil_03/leis/L9433.htm>. Acesso em: 26 abr. 2013.

${ }^{38}$ BRASIL. Lei $n^{\circ}$ 9.984, de 17 de julho de 2000, op cit. 
respeitando-se os prazos máximos de até dois anos para o início da implantação do empreendimento e até seis anos para conclusão.

Os prazos de vigência das outorgas também são definidos levando-se em conta fatores característicos de cada empreendimento. Também cabem aos Comitês de Bacias Hidrográficas definirem, a partir de dados como a natureza do empreendimento, período de investimento, finalidade, importância no desenvolvimento social e econômico, quais deverão ser os prazos para as outorgas concedidas.

Em caso de descumprimento do que está estabelecido na legislação, surge à necessidade de suspensão da outorga concedida. As previsões de suspensão parcial ou total da outorga se encontram no art. 15 da Lei n. ${ }^{\circ} 9.433 / 97$ que estabelece:

\footnotetext{
Art. 15. A outorga de direito de uso de recursos hídricos poderá ser suspensa parcial ou totalmente, em definitivo ou por prazo determinado, nas seguintes circunstâncias:

I - não cumprimento pelo outorgado dos termos da outorga;

II - ausência de uso por três anos consecutivos;

III - necessidade premente de água para atender a situações de calamidade, inclusive as decorrentes de condições climáticas adversas;

IV - necessidade de se prevenir ou reverter grave degradação ambiental;

V - necessidade de se atender a usos prioritários, de interesse coletivo, para os quais não se disponha de fontes alternativas;

$\mathrm{VI}$ - necessidade de serem mantidas as características de navegabilidade do corpo de água. ${ }^{39}$
}

Novamente a outorga encontra-se lado a lado com a garantia de transindividualidade do recurso hídrico visto que a suspensão deve ser aplicada sempre que o uso coletivo necessitar se sobrepor. Claro que a suspensão deve ser alicerçada por estudos técnicos que comprovem sua real necessidade. Machado afirma que a suspensão irá ocorrer por circunstâncias que não são de responsabilidade da Administração Pública e nem de responsabilidade do outorgado, é o interesse público geral que tornará necessária a suspensão, devendo esta ser revestida de proporcionalidade e não cabendo indenização ao outorgado. Claro é o não direito a indenização,

\footnotetext{
${ }^{39}$ BRASIL. Lei $\mathrm{n}^{\circ}$ 9.433, de 8 de janeiro de 1997. Institui a Política Nacional de Recursos Hídricos, cria o Sistema Nacional de Gerenciamento de Recursos Hídricos, regulamenta o inciso XIX do art. 21 da Constituição Federal, e altera o art. $1^{\circ}$ da Lei $n^{\circ} 8.001$, de 13 de março de 1990 , que modificou a Lei $n^{\circ}$ 7.990, de 28 de dezembro de 1989. Diário Oficial [da República Federativa do Brasil], Brasília, DF. Disponível em: <http://www.planalto.gov.br/ccivil_03/leis/L9433.htm>. Acesso em: 26 abr. 2013.
} 


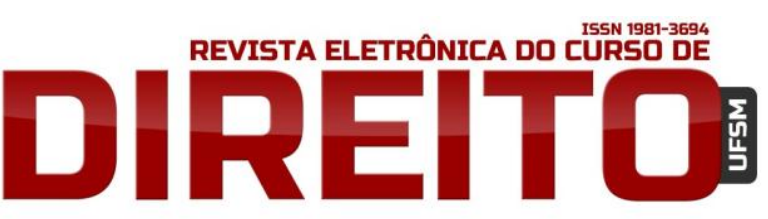

A NOVA NATUREZA JURÍDICA DA ÁGUA E SUAS CONSEQUÊNCIAS EM FACE DA OUTORGA DE DIREITO DE USO DE RECURSOS HÍDRICOS.

TONY CARLO SOUZA SILVA JOHNSON QUEIROZ VILAS BOAS

visto se tratar de um bem que notoriamente tem cunho não individual e apenas era utilizado através de autorização do Poder Público que é o responsável por sua gestão. ${ }^{40}$

\subsection{Competência para autorização de outorgas}

No âmbito federal é de competência da ANA - Agência Nacional das Águas - autorizar outorga de recursos hídricos. Já no âmbito estadual os Estados e o Distrito Federal têm órgãos próprios com competência legal para autorizar outorgas.

A ANA é uma autarquia federal vinculada ao ministério do Meio Ambiente e foi criada pela Lei $n .^{\circ} 9.984 / 00^{41}$ sendo responsável pela política Nacional dos Recursos Hídricos. É uma agência reguladora responsável por garantir o cumprimento da Lei n. ${ }^{\circ} 9.433 / 97 .{ }^{42}$

A competência para autorizar outorgas no âmbito federal é regida pela Lei $n .^{\circ}$ 9.984/00 em seus arts., $4^{\circ}$, inciso IV, e 12 , inciso $\mathrm{V}^{43}$, como também pela Lei $\mathrm{n} .^{\circ}$ 9.433/97 em seu artigo 14 , § $1^{044}$. Para Granziera, a competência da União para conceder outorgas de direito de uso de recursos hídricos é delegável podendo ficar a cargo de cada Unidade Federativa de acordo com o interesse público de cada situação podendo ser percebida também a natureza do recurso hídrico de bem pertencente a todos. ${ }^{45}$

\footnotetext{
40 MACHADO, Paulo Affonso Leme. Curso de Direito Ambiental Brasileiro. 17. ed. São Paulo: Malheiros, 2009.

${ }^{41}$ BRASIL. Lei ${ }^{\circ}$ 9.984, de 17 de julho de 2000. Dispõe sobre a criação da Agência Nacional de Águas ANA, entidade federal de implementação da Política Nacional de Recursos Hídricos e de coordenação do Sistema Nacional de Gerenciamento de Recursos Hídricos, e dá outras providências. Diário Oficial [da República Federativa do Brasil], Brasília, DF. Disponível em:<http://www.planalto.gov.br/ccivil_03/leis/L9984.htm>. Acesso em: 26 abr. 2013.

${ }^{42}$ BRASIL. Lei ${ }^{\circ}$ 9.433, de 8 de janeiro de 1997. Institui a Política Nacional de Recursos Hídricos, cria o Sistema Nacional de Gerenciamento de Recursos Hídricos, regulamenta o inciso XIX do art. 21 da Constituição Federal, e altera o art. $1^{\circ}$ da Lei $n^{\circ} 8.001$, de 13 de março de 1990, que modificou a Lei ${ }^{\circ}$ 7.990, de 28 de dezembro de 1989. Diário Oficial [da República Federativa do Brasil], Brasília, DF. Disponível em: <http://www.planalto.gov.br/ccivil_03/leis/L9433.htm>. Acesso em: 26 abr. 2013.

${ }^{43}$ BRASIL. Lei ${ }^{\circ} \mathbf{9 . 9 8 4}$, de 17 de julho de 2000, op. cit.

${ }^{44}$ BRASIL. Lei $n^{\circ}$ 9.433, de 8 de janeiro de 1997, op. cit.

45 GRANZIERA, Maria Luiza Machado. Direito de Águas: disciplina jurídica das águas doces. 3. ed. São Paulo: Atlas, 2006.
} 


\section{CONCLUSÃO}

Diante do exposto, pode-se dizer em suma que: a CRFB/88 não deixa dúvidas quanto à natureza jurídica da água. Isto porque o enunciado previsto no caput do art. 225 da Lei Maior dispõe que o meio ambiente é bem de uso comum do povo. Isto faz com que o referido enunciado se aplique à água, por ser este elemento corpóreo que integra o meio ambiente. A água é, destarte, um bem que possui natureza transindividual, ou seja, transcendem o indivíduo, ultrapassa o limite da esfera de direitos e obrigações de cunho individual. Este recurso natural pertence, ipso facto, a todos, mas, ao mesmo tempo, ninguém especificamente o possui. Por derradeiro, verificou-se que a água não é um bem que integra o patrimônio do Poder Público, haja vista que ele é apenas seu gestor. Por conta disso que a Lei Maior impõe não só ao Poder Público, como também a coletividade o dever de defender e preservar o recurso hídrico para as presentes e futuras gerações.

Além do mais, partindo da premissa desta nova natureza jurídica que a CRFB/88 trouxe à água, desta forma, que a água não se enquadra na categoria de bem público, e muito menos privado. A água, na verdade, é um bem que possui natureza de bem difuso. Em consequência disso, faz-se necessário reclassificar os bens em: a) bens privados; b) bens públicos; c) bens ambientais (bem de uso comum do povo ou difuso). Esta última categoria de bem está situada numa faixa intermediária entre o público e privado. Não sendo possível identificar o seu titular, e o seu objeto é indivisível.

Essa nova classificação da água inviabilizou a alienação da água, como também a privatização de mercantilização dos recursos hídricos; provocou o repúdio a qualquer forma de poluição ou agressão deste bem natural; dentre outras consequências. Além do mais, a atual natureza jurídica da água provocou modificações também em face da outorga do seu direito de uso, uma vez que a outorga, ferramenta desenvolvida pela Política Nacional dos Recursos Hídricos, tem extrema importância no que se refere ao uso democrático dos recursos hídricos. 0 Estado, como gestor das águas, é o responsável por conceder as autorizações de outorga levando em conta, principalmente, critérios de justiça.

A água, por ser um bem de todos e ao mesmo tempo de ninguém, no momento do seu uso, deve ser racionalizada de forma que atenda a todos os interesses envolvidos em seu entorno, desde biológicos até os econômicos. A outorga é o instrumento utilizado para a racionalização do uso, e não implica a alienação dos recursos hídricos. 
A legislação define vários tipos de uso em relação à outorga, como os usos dependentes da autorização, normalmente devido ao seu impacto, os usos independentes de autorização por serem de extrema necessidade, os usos insignificantes que devido ao pequeno impacto ficam dispensados de outorga e existe até mesmo a previsão do uso da água, que por meio da outorga preventiva, reserva determinada quantidade de recurso hídrico a uma aplicação distinta de forma legal.

A outorga se revela um dispositivo altamente funcional capaz de considerar os usos concorrentes e múltiplos da água, ou seja, todos querem ter seu quinhão de utilização do recurso, e ao mesmo tempo, são várias as aplicações dadas a tal recurso. Em circunstâncias de uso descontrolado as fontes de recursos hídricos podem sucumbir em face da poluição, degradação e utilização sem parametrização adequada à regeneração do ambiente, consequências essas, que podem ser evitadas lançando-se mão da outorga.

Enfim, a Política Nacional dos Recursos Hídricos surge como base para direcionar a utilização dos recursos hídricos e traz em seu cerne a outorga, que se apresenta como grande ferramenta, indispensável na gestão do elemento água. Não obstante caber ao Estado conceder as autorizações e fiscalizar o uso consciente da água, cabe também aos usuários, diretamente interessados, cuidar para que tal elemento de vital importância se mantenha disponível para muitas gerações.

\section{REFERÊNCIAS}

BRASIL. Constituição da República Federativa do Brasil de 1988. Diário Oficial [da República Federativa do Brasil], Brasília, DF. Disponível em:

<http://www.planalto.gov.br/ccivil_03/constituicao/constituicaocompilado.htm>. Acesso em: 26 abr. 2013.

Decreto $n^{\circ} 24.643$, de 10 de julho de 1934. Decreta o Código de Águas. Diário Oficial [da República Federativa do Brasil], Brasília, DF. Disponível em:<

http://www.planalto.gov.br/ccivil_03/decreto/d24643.htm>. Acesso em: 26 abr. 2013.

. Instrução Normativa $n^{\circ} 4$, de 8 de setembro de 2009 . Dispõe sobre

procedimentos técnicos para a utilização da vegetação da Reserva Legal sob

regime de manejo florestal sustentável, e dá outras providências. Ministério do Meio Ambiente. Disponível em: <http://www.ibama.gov.br/sophia/cnia/legislacao/MMA/IN0004-090909.PDF>. Acesso em: 26 abr. 2013. 


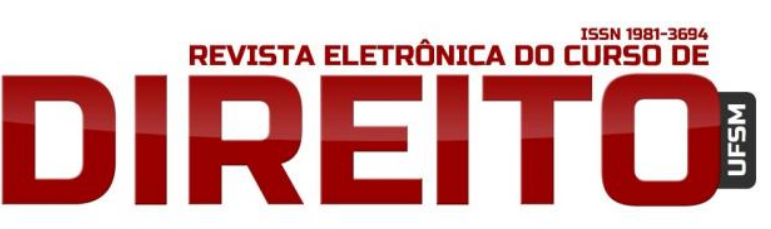

A NOVA NATUREZA JURÍDICA DA ÁGUA E SUAS CONSEQUÊNCIAS EM FACE DA OUTORGA DE DIREITO DE USO DE RECURSOS

HÍDRICOS.

. Lei $\mathrm{n}^{\circ} \mathbf{8 . 0 7 8}$, de 11 de setembro de 1990 . Dispõe sobre a proteção do consumidor e dá outras providências. Diário Oficial [da República Federativa do Brasil], Brasília, DF. Disponível em: <http://www.planalto.gov.br/ccivil_03/leis/L8078.htm>. Acesso em: 26 abr. 2013.

. Lei $\mathrm{n}^{\circ}$ 9.433, de 8 de janeiro de 1997. Institui a Política Nacional de Recursos Hídricos, cria o Sistema Nacional de Gerenciamento de Recursos Hídricos, regulamenta o inciso XIX do art. 21 da Constituição Federal, e altera o art. $1^{\circ}$ da Lei ${ }^{\circ} 8.001$, de 13 de março de 1990, que modificou a Lei n 7.990, de 28 de dezembro de 1989. Diário Oficial [da República Federativa do Brasil], Brasília, DF. Disponível em:

<http://www.planalto.gov.br/ccivil_03/leis/L9433.htm>. Acesso em: 26 abr. 2013.

. Lei $\mathrm{n}^{\circ}$ 9.984, de 17 de julho de 2000. Dispõe sobre a criação da Agência Nacional de Águas - ANA, entidade federal de implementação da Política Nacional de Recursos Hídricos e de coordenação do Sistema Nacional de Gerenciamento de Recursos Hídricos, e dá outras providências. Diário Oficial [da República Federativa do Brasil], Brasília, DF. Disponível em:<http://www.planalto.gov.br/ccivil_03/leis/L9984.htm>. Acesso em: 26 abr. 2013.

. Lei $\mathrm{n}^{\circ}$ 10.406, de 10 de janeiro de 2002. Institui o Código Civil. Diário Oficial [da República Federativa do Brasil], Brasília, DF. Disponível em:

<http://www.planalto.gov.br/ccivil_03/leis/2002//10406.htm>. Acesso em: 24 jul. 2013.

FIORILLO, Celso Antonio Pacheco. Curso de direito ambiental brasileiro. 13. ed. rev., atual. e ampl. São Paulo: Saraiva, 2012.

GRANZIERA, Maria Luiza Machado. Direito de Águas: disciplina jurídica das águas doces. 3. ed. São Paulo: Atlas, 2006.

2000.

Revista do Centro de Estudos Judiciários. Brasília. n 12, p. 71-74, set/dez.

MACHADO, Paulo Affonso Leme. Curso de Direito Ambiental Brasileiro. 17. ed. São Paulo: Malheiros, 2009.

Direito ambiental brasileiro. 3. ed. São Paulo: Revista dos Tribunais, 1991.

NOVELINO, Marcelo; CUNHA JUNIOR, Dirley da Constituição Federal para Concursos. 2. ed. Salvador: JusPodivm, 2011. 
SIRVINSKAS, Luís Paulo. Manual de Direito Ambiental. 7.ed. São Paulo: Saraiva, 2009.

TERZI, Alex Mourão; PEREIRA, Pedro Henrique Santana. Educação Ambiental como Direito Fundamental: necessidade de uma abordagem interdisciplinar. Revista Saberes Interdisciplinares. Volume 4. $\mathrm{n}^{\circ}$ 7. Ano 2011.

2011. Disponível em:

<http://www.iptan.edu.br/publicacoes/saberes_interdisciplinares/pdf/revista07/EDUCACAO_A MBIENTAL_COMO_DIREITO_FUNDAMENTAL.pdf >. Acesso em: 26 abr. 2013.

YOSHIDA, Consuelo Yatsuda Moromizato. Água: bem privado, bem público ou bem difuso. Implicações jurídicas, econômico-financeiras e sócio-ambientais. Recursos Hídricos: aspectos éticos, jurídicos, econômicos e socioambientais. v. 2. Campinas: Alínea, 2007.

Recebido em: 01 maio. 2013

Revisões requeridas: 15 jul. 2013

Aprovado em: 28 jul. 2013 